\title{
A new generation of classroom studies
}

\author{
Kirsti Klette
}

Classroom observation studies used as a lens to understand the features of teaching and learning processes are part of a long tradition, whether internationally or in the Nordic countries. Starting in the late $1960 \mathrm{~s}$ (see, for example, Jackson 1968; Flanders 1970; Brophy \& Good 1974; Callewaert \& Nilsson 1974; Borgnakke 1979), they have been seen as a more authentic (Nielsen 1985) and reliable way of understanding school and classroom learning. Since the early phase in the late 1960 , classroom research has been established to be a methodological approach that covers the full range of aspects that are central to classroom learning, such as communication processes and interaction patterns (Bellack et al. 1966; Sinclair \& Coulthard 1992; Sahlström 1999; Cazden 2001; Andersson-Bakken \& Klette 2015), functional classroom activities and instructional repertoires (Brophy \& Good 1974; Doyle 1975; Lindblad \& Sahlström 1999; Klette 2004 \& 2015), and students' role and identities (Nielsen 1988; Lyng 2004; Bakken \& Borg 2008; Öhrn 2012)—and, since the late 1990s, subject-specific repertoires and practices (Nystrand 1997; Boaler 1997; Mortimore \& Scott 2003; Ødegaard \& Klette 2012; Berge \& Ingerman 2016). All the approaches listed, and especially the latter (e.g. subject specific approaches), correspond to the didactic classroom studies of the present volume. Today, classroom research designs serves as the methodological grounds for at least three distinct research traditions, which, as Erickson (2006) 
argues, are (i) discourse or interaction analyses, which centre on micro-analyses of language and communication; (ii) process or product approaches, which concentrate on functional classroom interaction and activities; and (iii) teachers' professional knowledge or pedagogical content knowledge, in which the main interests are interaction, the activities linked to the subject matter, and meaning-making linked to content. This concluding essay is especially concerned with the latter position, the use of subject-specific investigations of Swedish primary and secondary school classrooms and beyond.

While video recordings were used in some of early classroom studies (see Sherin 2004), videos were never part of a common toolbox, and for a long time (with the exception of the TIMSS Video Study), audio, together with field notes, classroom diaries, and/or predefined observation schemes, was the basic methodological instrument when gathering in situ classroom data. Recent developments in video technology, with small, miniaturised, discrete cameras that support software tools for analysis, together with improvements in methodologies and an integrated methodological design, however, have enabled the combination of in-depth data from classrooms with large-scale data sets, such as student questionnaires and achievement scores (Fischer \& Neumann 2012; Klette 2015). Nested, integrated designs and new technologies have paved the way for a new wave of classroom studies along the lines of large-scale classroom studieshence the Measuring Effectiveness in Teaching (MET) study (MET project 2012), the OECD TALIS Video Study (Decristan et al. 2015; OECD 2016), and the Linking Instruction and Achievement study (Klette et al. 2017). Targeted, subject-specific studies (see for example, Grossman et al. 2013; Lipowsky et al. 2009) have further fuelled interest in classroom research as a way of understanding teaching and learning processes. The contributions to the present volume feed into this with their spectrum of classroom data (videos, field notes, interviews, textual and visual resources, tasks, and, in some cases, achievement scores) used to gauge the multiple meanings of institutional classroom teaching and learning.

Alongside this move in research design, there is plainly considerable consensus on the analytical approaches and frameworks for analysing 
teaching and learning processes, with an emphasis on teaching and learning as normative and institutional activities that occur at the intersection between the content involved and accompanying students' or teachers' interactions. Thus, frameworks for analysing the dimensions of teaching and learning need to be sensitive to a range of dimensions such as cognitive demands and challenges, pupils' or students' and teachers' communication patterns, and clarity of instruction. These also include teachers' use of instructional activities and scaffolding techniques, and a classroom climate that creates an environment of trust and is open to students' perspectives and needs. If we examine the various frameworks (see, for example, Seidel \& Shavelson 2007; Lipowsky et al. 2009; Kane \& Staiger 2012; Klette 2015; Nilsen \& Gustafsson 2016), five dimensions stand out as especially critical in understanding the key features of classroom teaching and learning: instructional clarity, cognitive demand and activation, discourse features, a supportive climate, and activity structure.

These five dimensions of classroom processes, as distinct analytical approaches - for features of classroom discourse and meaning-making, see, for example, Mortimore and Scott (2003) - or as a coherent framework operationalised at the level of an observation manual-the CLASS observation manual (Pianta et al. 2008), say, or the Framework For Teaching manual (Danielsson 2011) —are often understood as the common analytical ground in today's studies of classroom teaching and learning. Despite their shared basis, however, analytical frameworks vary in how targeted and subject-specific they are, their units of analysis, how fine-grained they are, and whether their primary focus is the teachers' or the students' actions. They further differ in their theoretical and conceptual grounding of teaching and learning and their procedures for analysis. The current volume feeds into this discussion, representing both generic and subject-specific classroom studies and using analytical framings that relate to the entire spectrum listed.

In this essay, I thus comment on the research ambition of the present volume by summarising developments in classroom research designs, especially how recent developments in video design have contributed to renewing and thus vitalising this area of research, 
including the contributions represented in this volume. I then discuss how the present essays relate to the spectrum of analytical dimensions listed above, or, in other words, how empirical enquiries into subject specificity and unit of analysis turn on conceptions of learning and theoretical approaches.

\section{A new generation of video studies}

Scholars agree that video analysis has multiple and significant advantages in developing our understanding of teaching and learning processes (Hiebert 2003; Janík \& Seidel 2009; Fischer \& Neumann 2012). Clarke and colleagues argue that video recordings '... provide a much richer portrayal of classroom practices than would be possible from any single analysis' $(2006,6)$. Drawing on video documentations from science classrooms, Fischer and Neumann (2012) claim that video studies are especially interesting for probing quality in teaching, because such studies can capture pupils' and teachers' behaviours in one package.

Video can reveal classroom practices more clearly, facilitate the discovery of new alternatives, and stimulate discussions about the pedagogical choices in each classroom, so deepening educators' understandings of teaching. Video also facilitates the study of complex processes and the integration of qualitative and quantitative analyses. It enables coding from multiple perspectives, and new ways of communicating findings and results. Furthermore, video data can be stored in a form that allows subsequent and novel analyses, fruitful data combinations, and collaborative analyses. Video studies have proved to be valuable tools for investigating instruction both at the level of individual teachers and in larger studies involving samples of teachers from a country or region, as well as between countries or regions. Video analysis allows the identification of subject-specific patterns of instruction and cultural scripts (Stigler \& Hiebert 1999).

The growing interest in video can be traced to the rapid development of technology that allows easy storage and online streaming. Video equipment is now miniaturised, portable, remote controlled, and operated by researchers or teachers themselves, thus making such 
studies feasible and less intrusive on everyday life in the classroom. New technologies have been matched by major developments in coding and processing, software for video data analysis (for example, Studio Code, Interact, Observer XT), and systems and infrastructure that facilitate the sharing of data and targeted and integrative analyses.

One of the benefits of video capture or video data from classrooms is that it enables analyses that combine the subject-specific and generic features of teaching and learning. Video data also provide opportunities to combine different analytical and theoretical approaches to the same data set. Berge and Ingerman (2016), for example, combine variation theory and conversation analysis to understand the features of science teaching and learning among undergraduates. Likewise, Ødegaard \& Klette (2012) combine process-product approaches in teaching and learning (instructional format and activity structures) with subject-specific dimensions (conceptual language used, quality of explanations, etc.) when analysing science teaching in Norwegian secondary school classrooms. In the present volume, Rocksén uses different timescales and units of analysis to discuss how pupils' science-related talk develops over time and across sequences of lessons, arguing that several measuring points and a variety of timescales are relevant to understanding how pupils learn.

Recent reviews of coding protocols and frameworks for analysing classroom data (Klette \& Blikstad-Balas 2018; Bell et al. in press) have emphasized how analytical frameworks and coding procedures might differ in analytical focus and granularity, in generic versus subject-specific frameworks, and in views and conceptualizations of teaching and learning. Methodological variation needs to be considered too. This refers to how different 'observation systems' (Bell et al. in press) differ in their time segments for coding, explicitness of rubrics and scales for analyses and scoring, and required training and certification. I use these aspects here to evaluate the research goal of the present volume by comparing empirical outcomes with the theoretical and methodological approaches employed. 


\section{Analytical frameworks}

Developments in video design, then, have paved the way for a renewed interest in shared analytical frameworks and observation schemes when analysing the features of teaching. Earlier observation schemes and protocols were primarily mapping surface structure of teaching and learning (Siedel \& Prenzel 2006) and/or trivial aspects of classroom teaching and learning (Ko \& Simmons 2010; Scheerens 2014). More recent protocols and frameworks are more targeted, and capture either generic (Pianta et al. 2008; Danielsson 2011) or more subject-specific (Hill et al. 2008; Grossman et al. 2013) aspects of teaching and learning. They have also been thoroughly validated in large-scale empirical studies (Archer et al. 2012), and their consistency is strengthened by the elaboration of procedures for scoring and coding that meet specific certification and training requirements. The different analytical frameworks or protocols might also vary in terms of the aforementioned factors-views on teaching and learning, units of analysis, and teacher and/or pupil/ student focus.

The essays in the present volume illustrate different ways of handling these challenges, but none of them use a standard observation protocol or framework. On the contrary, each of the studies uses its own analytical and conceptual framework, consistent with the existing analytical approaches in its respective theoretical tradition (variation theory, interaction analysis, semiotic analysis, etc.), or it draws on existing practices, consistent with prior research conducted in its respective area (for example, Lilja \& Claesson, Kilhamn et al.). Below, I comment on the dimensions of the analyses used in the current volume, and argue how the various frameworks and approaches might produce new and significant, but also different and possibly inconsistent findings, guided in my exercise by the following factors: views on teaching and learning, units of analysis, analysing teachers' actions versus pupils' actions, generic versus subject-specific analyses, and individual analyses versus joint analyses. 


\section{Views on teaching and learning}

The essays presented in this volume use a broad spectrum of theories of learning when investigating classroom teaching and learning, spanning everything from socio-cultural and dialogic approaches to learning, semiotic analysis, and variation theory, to more subjectspecific theories required when learning mathematics, for example, as mathematical knowledge for teaching (MKT) (see Ball et al. 2008).

Variation theories and semiotic analyses feature in four out of the nine essays. Kullberg and Skodras, like Ingerman and Booth, use variation theories in their analytical approach, whereas Sofkova Hashemi and Hipkiss both draw on social semiotic analyses. However, while drawing on the same theoretical grounding and framework, the analyses as practices in the same tradition differ radically in scale and preferred analytical concepts. Ingerman and Booth, for example, analyse meaning-making in shared discussions of a joint problem in physics education, showing how groups of students vary in the way they deal with the problem at hand. The authors argue that a more fruitful discussion might occur if the groups were composed more carefully, or if they had a more careful combination of students and tasks that had the appropriate relevance and levels of difficulty. Thus, the authors use variations in content-related communication and discussion as their analytical tools. Kullberg and Skodras also drawing on variation theory, focus on teachers' selection and use of examples in middle-school mathematics classrooms to discuss how the different ways of using and displaying examples provide substantially different learning experiences for the pupils. The authors state that the teachers' careful selection, use and presentation of examples, supported by a clear conceptual focus, are decisive for the pupils' opportunities to experience the content in question. The authors' analytical focus is the selection of examples and supporting visual models and accompanying discussions as representations for possible pathways of content learning in mathematics. Drawing on the same theoretical framework (for example, variation theory), Ingerman and Booth see difficulty level and group composition as constraints to possible learning, whereas Kullberg and Skodras 
highlight the ways of representing content, as illustrated by the teachers' use of examples as critical for learning. Thus, the authors do not use joint concepts in their empirical inquiries, but rather use variation design (systematic comparison of similar cases and units) as a key strategy. Contrary to many other theoretical traditions that built their analysis around some key concepts or dimensions and categories to be studied (such as types of questions, use of uptake and responses, and turn-taking in interaction analyses), variation theories allow a systematic comparison between two or more similar cases. However, the unit of analysis and key concepts pursued differ substantially.

Two essays, Sofkova Hashemi and Hipkiss, use semiotic theoretical perspectives to underscore an analogous argument. Although drawing on related theoretical frames and views of learning, they use different key categories and concepts in their analyses. Sofkova Hashemi categorises semiotic resources and tools in terms of type and the relative distribution of time spent on writing, speaking, listening, and so on seen in the different classrooms, and qualifies these activities according to multidimensional criteria. Hipkiss, who also draws on semiotic analyses, uses concepts and categories such as monologues, dialogic exchanges and participatory exchanges, together with spatial features, to analyse interpersonal interaction and differential spatial affordances in the classroom. As such, Hipkiss' categories and lenses for analysing her data share more similarities with the concepts used in the essays in which socio-cultural theories (Osbeck) and theories of communication (Rocksén) are the preferred theoretical perspective. The analyses in Osbeck's and Rocksén's essays use conceptual categories, such as open-ended and closed questions, inferential utterances, interpretative utterances (Osbeck), and dialogues versus monologues and teacher-directed dialogues (Rocksén) - all concepts that are not far from those deployed by Hipkiss, drawing on semiotic analyses.

The point to be made here is twofold. First, similar studies with similar theoretical perspectives do not necessarily share a conceptual framework, operationalisation, or reported levels of analysis. Variation theory and social semiotics representing two distinct 
theoretical traditions offer a set of approaches (variation theory) or a set of concepts/conceptual categorisations that both provide a large degree of freedom when researchers conduct their analysis. Thus, categories at the empirical level may differ substantially between researchers belonging to the similar traditions and pursuing similar theoretical goals.

Second, because of the discrepancies between the theoretical and empirical definitions of categories in the essays, it is tempting to follow the suggestion by Thomas (2007) and Hammersley (2012) that we should look closer at the 'language games' played when referring to theoretical frameworks or theorising. A conceptual level that is closer to the actual analytical work may provide the template for exploring how different categories delineate similar or different phenomena and how they process outcomes, as well as the extent to which these are consistent with higher-order theoretical concepts. This endeavour is only partly done in the present volume. Such an approach that is close to the data and analyses might contribute to strengthening cross-case analyses and syntheses when conducting didactic classroom studies; therefore, it also contributes to more systematic and programmatic research to understand the different theoretical traditions and conceptualisations that teaching and learning might add to our understanding of the formal processes in classroom learning, as will be seen when considering individual analyses versus joint analyses below.

\section{Units of analysis}

The essays differ in granularity and unit of analysis, thus putting conceptual demands on both researchers and readers. While a holistic research design (Day et al. 2010b) might have the goal of grasping the multidimensional and complex character of classroom learning, it often suffers from grasping surface aspects (Seidel \& Prenzel 2006) of classroom teaching and learning, thus tending to reproduce what we already know (Hammersley 2008). Being explicit about the unit of analysis is one way to reduce these complexities. The unit of analysis could be a single pupil or student, a group of pupils or the entire class, 
or the teacher or teachers. However, it could also be a single task or a problem-solving phase, or how different series and time segments might produce different conditions for learning, such as the example used by Rocksén in this volume. Preferences connected to the unit of analysis will, however, have strong implications on the empirical focus, the selection of the data required and the presentation of the data.

In the present volume, the unit of analysis focuses on an adjusted version of the didactic triad-teachers' and students' activities, communication and meaning-making linked to a specific content. Kullberg and Skodras, Osbeck, and to an extent Lilja and Claesson are explicit about using teachers as their basic unit of analysis: they draw on data from mathematics or religious education classrooms, as well as look across different classrooms (Lilja \& Claesson). Kullberg and Skodras, as well as Osbeck, are explicit about teachers' use of examples as their basic unit of analysis. They differ in their ambition of scale, however. Kullberg and Skodras link teacher strategies to targeted analyses of variations in teachers' use of examples (and supporting scaffolding strategies), and they show how teaching strategies (use of examples in mathematics) and aspects of the content together shed light on pupils' opportunities to learn. Osbeck, on the other hand, discusses teachers' orchestration of classroom communication by using teachers' and pupils' joint classroom talk as the pitch of her analysis, operating on the level of the community or group and on a more aggregated level. Lilja and Claesson, as a third example, investigate teachers' ability to move between instructional strategies as a focal unit for analysing teachers' capacity to maintain discipline in the classroom. However, the way they have conceptualised order and discipline, together with the level of detail, tends to produce rather generic knowledge. A more systematic, targeted focus and unit of analysis might have produced stronger evidence for the claims they make.

\section{Teachers' actions, students' actions, or both?}

Three of the essays in this volume explicitly focus on students' or pupils' actions (Sofkova Hashemi, Ingerman \& Booth, Hipkiss), one essay focuses on teachers' actions only (Kullberg \& Skodras) and 
the five other essays focus on both pupils' and teachers' actions. As teachers or pupils seldom engage in stand-alone activities but take part in a chain of interactions and interlinked relationships and activities, scholars conducting classroom research need to situate their analyses in a larger landscape and segments of actions and meaning. To analyse learning from pupils' perspective, one most often needs to include the teacher's activities and utterances, as well as those of the other pupils, so that the processes can be understood. Social semiotic analyses, as performed in this volume (Sofkova Hashemi, Hipkiss), represent a distinct approach for keeping track of pupils' perspectives, I would argue, even when teachers' actions are included in the analyses. Their conceptual framing and categories seem to work well when keeping track of the pupils and keeping them in focus. As content cannot be analysed alone, it moves at the intersection between the three key partners - the pupils, the teachers, and the content involved-several of the essays in this volume include the focal content in their analyses. There is, however, as I have argued elsewhere (Klette 2007), a danger for privileging interaction at the cost of in-depth analyses of the content, thus reducing content learning to interaction and communication patterns.

\section{Generic versus subject-specific}

Most of the essays argue for a subject-specific approach using the didactic triad as a baseline for their study. Some essays work at the intersection of content and teacher actions, whereas others are interested in how pupils might engage with content as their primary interest. Only one of the essays uses what might be called a subject-specific framework when analysing the focal content: this is Kilhamn et al.s essay, which draws on mathematical knowledge for teaching, developed by Ball and colleagues (Ball et al. 2008). Whilst not representing subject-specific approaches, variation theory, and social semiotics, three essays in this volume (Osbeck, Ingerman \& Booth, Sofkova Hashemi), however, come close to subject- and content-specific analyses, as they draw on a theoretical grounding and a conceptual toolbox that nurture content-related analyses. 
These frameworks (variation theory, theory of semiotics) are not subject specific; they are generic and could be applied to all types of content areas. In these cases, the conceptual specificity, together with the granularity, however, produce targeted and thus subjectrelevant analyses.

Internationally, several scholars argue for the need for subject specificity when analysing the qualities of classroom teaching and learning. Hill and Grossman (2013) argue that if classroom analyses were to achieve the goal of supporting teachers in improving their teaching, these frameworks must be subject specific and involve content expertise. This will enable teachers to provide information that is relevant for their situation-specific teaching objectives, regardless of whether these are student participation, algebra learning, or group problem-solving. Blömeke et al. (2015) show how a combination of generic factors and subject-specific factors (in their case, mathematics) is required for producing valid knowledge about how different teaching factors contribute to student learning. Klette et al. (2017) use a specific analytical framework (targeted for English-language arts education) to capture both subject-specific and generic goals when analysing the features of Norwegian-language arts and mathematics instruction. One goal in the Klette et al. (2017) study is to analyse how and to what extent subject-specific frameworks might work across different content areas.

\section{Individual versus programmatic analyses}

As already mentioned, none of the essays in the present volume systematically develop or draw on the same analytical framework. A more programmatic approach might be required to produce sustainable and robust findings when trying to understand the critical components in classroom teaching and learning. The relational dynamics between classroom teaching and learning are not well understood, and integrated frameworks 'that link instructional activities and procedures (the how) with thematic patterns (the what) and mode of interactions (the who)' (Klette 2007, 148) are needed. One promising way to go forward in the field of didactic 
classroom studies is to use a more programmatic approach in which researchers with a shared tradition, view of teaching, and learning or subject expertise area address a set of questions and analytical approaches systematically and over time.

Like Grossman and Macdonald (2008), I would argue that to advance in the area of didactic classroom studies our next step should be to move beyond single case studies towards more programmatic research that addresses a set of critical questions over time and in different settings and subject areas. To this end, we need integrative and synthesising manoeuvres that can summarise how different frameworks and conceptual enquiries might produce patterns and possible findings, as well as the use of these to investigate how the range of such findings might vary across contexts, subjects, groups of students, classrooms, and school environments. Likewise, we need common analytical frameworks and instruments that can discern the possible impacts and implications of these across sites and classroom settings. Using variation design to systematically investigate the role of group discussions and the role of examples for learning across school years, subject areas and groups of students could be one way to pursue such a goal. Applying different analytical frameworks and conceptual framings in examining the features and challenges in a specific subject area, such as algebra learning, could be another way. A third approach could be using the same analytical framework in different topics and subjects to push our understanding of the potential power of a specific feature of classroom learning, such as classroom discussion. Reviews of research on the impact of classroom discourses, for example, point to mixed and rather inconsistent findings (Howe \& Abedin 2013) about when classroom discourses are productive or are not of critical interest.

\section{A future for content-focused classroom studies}

The present volume presents a solid, empirically grounded attempt to understand the complexities of classroom teaching. A special value is how the different contributions take on the challenge of setting out analysis that moves at the intersection of teachers, students, and 
the content involved. Unlike similar studies, this volume seriously considers the role of content and how the content in classroom learning might produce rather different contexts for learning. One of its strengths, of course, is the spectrum of theoretical perspectives applied by the authors.

Classrooms and students vary, and subject-specific and targeted analyses are required to make this research useful for teachers. We need information about how the features of classroom teaching and learning might work for different types of students, group compositions, and types of learning goals, regardless of whether they are cognitive, social, motivational, and so on. For this, multiple frameworks and instruments are required. Thus, the next phase for didactic classroom studies might be what I have described as a programmatic approach to classroom studies, systematically investigating the key features of classroom teaching and learning across years, content areas, environments, and groups of students.

\section{References}

Andersson-Bakken, E. \& K. Klette (2015), 'Teachers' Use of Questions and Responses to Students' Contributions During Whole Class Discussions: Comparing Language Arts and Science Classrooms', in K. Klette, O. K. Bergem \& A. Roe (eds.), Teaching and Learning in Lower Secondary Schools in the Era of PISA and TIMSS (Cham: Springer).

Archer, J., S. Cantrell, S. L. Holtzman, J. N. Joe, C. M. Tocci \& J. Wood (2012), Better Feedback for Better Teaching: A Practical Guide to Improving Classroom Observations (San Francisco: Jossey-Bass) http://k12education.gatesfoundation. org/teachersupports/teacher-development/measuring effective-teaching/.

Bakken, A., E. Borg, K. Hegna \& E. Backe-Hansen (2008), Er det skolens skyld? En kunnskapsoversikt om skolens bidrag til kjønnsforskjeller i skoleprestasjoner (Oslo: Norsk institutt for forskning om oppvekst, velferd og aldring).

Ball, D. L., M. H. Thames \& G.C. Phelps (2008), 'Content Knowledge for Teaching: What Makes it Special?' Journal of Teacher Education, 59/5, 389-407. Bell, C., K. Klette, M. Dobbelaer, A. Visscher A. (2018), 'Qualities of classroom observation systems School Effectiveness and School Improvement, 1-27. An International Journal of Research, Policy and Practice (London: Routledge) Bellack, A. A., H. M. Kliebard, R. T. Hyman \& F. L. Smith (1966), The Language of the Classroom (USOE Cooperative Research Project, 2023; New York: Teachers College Press, Columbia University). 
Berge, M. \& Å. Ingerman (2016), 'Multiple theoretical lenses as an analytical strategy in researching group discussions', Research in Science \& Technological Education, 35/1, 42-57.

Bjerrum-Nielsen, H. (1985), 'Pedagogiske hverdagsbeskrivelser: Et forsømt område i pædagogisk forskning', Tidsskrift for Nordisk Forening for Pedagogisk Forskning, 2, 27-42.

-_ (1988), Jenter på østkanten: Når kvinneligheten blir synlig i klasserommet', in H. B. Nielsen (ed.), Jenteliv og likestillingsloere: Kjønnsroller og likestillingsarbeid blant ungdom (Oslo: Cappelen).

Blömeke, S., J.-E. Gustafsson \& R. J. Shavelson (2015), 'Beyond dichotomies: Competence viewed as a continuum', Zeitschrift für Psychologie, 3-13.

Boaler, J. (1997), Experiencing school mathematics: Traditional and reform approaches to teaching and their impact on student learning (Buckingham: Open University Press).

Borgnakke, K. (1979) (ed.), Project Skolesprog: Skoledage 1-2 (Copenhagen: GMT \& Unge Pædagoger).

Brophy, J. \& T. Good (1974), 'Classroom research: Some suggestions for the future', in eid., Teacher-student relationships: Causes and consequences (New York: Holt, Rinehart \& Winston).

Callewaert, S. \& B. A. Nilsson (1974), Samhället, skolan och skolans inre arbete (Lund: Lunds bok och tidskrift).

Cazden, C. (2001), Classroom discourse: The language of teaching and learning (Portsmouth: Heinemann).

Clarke, D., C. Keitel \& Y. Shimizu (2006) (eds.), Mathematics Classrooms in Twelve Countries: The Insider's Perspective (Rotterdam: Sense).

Danielson, C. (2011), The Framework for Teaching: Evaluation Instrument (Moorabbin, VIC: Hawker Brownlow Education).

Day, C. \& Q. Gu (2010) The New Lives of Teachers (London: Routledge).

_- _ _ - D. Hopkins, Q. Gu, E. Brown \& E. Ahtaridou (2010), School Leadership and Student Outcomes: Building and Sustaining Success (Maidenhead: Open University Press).

Decristan, J., E. Klieme, M. Kunter, J. Hochweber, G. Buttner, B. Fauth, A. L. Hondrich, S. Rieser, S. Hertel \& I. Hardy (2015), 'Embedded Formative Assessment and Classroom Process Quality: How Do They Interact in Promoting Science Understanding?' American Educational Research Journal, 52/6, 1133-59.

Doyle, W. (1975), 'Paradigms in Teacher Effectiveness Research', paper presented at the Annual Meeting of the American Educational Research Association, Washington, DC, April.

Erickson, F. (2006), 'Definitions and Analyses from Videotapes: Some research procedures and their rationales', in J. Green, G. Camilli \& P. B. Elmore (eds.), 
Handbook of Complementary Methods in Education Research (American Educational Research Association (AERA) Lawrence Erlbaum).

Fischer H. \& K. Neumann (2012), 'Video analysis as a tool for understanding science instruction', in D. Jorde \& J. Dillan (eds.), The World of Science Education (Rotterdam: Sense).

Flanders, N. (1970), Analyzing Teaching Behavior (Massachusetts: Addison Wesley).

Grossman P. \& M. McDonald (2008), 'Back to the Future: Directions for Research in Teaching and Teacher Education', American Educational Research Journal, 45/1, 184-205.

Grossman, P., S. Loeb, J. Cohen \& J. Wyckoff (2013), 'Measure for Measure: The relationship between measures of instructional practice in middle school English language arts and teachers' value added scores', American Journal of Education, 119, 445-70.

Hammersley, M. (2008), Questioning Qualitative Research: Critical Essays (London: SAGE).

- (2012), 'Troubling theory in case study research', Higher Education Research \& Development, 31/3, 393-405.

Hiebert, J. \& D. A. Grouws (2007), 'The effects of classroom mathematics teaching on students' learning', in F. K. Lester (ed.), Second handbook of research on mathematics teaching and learning (Charlotte, NC: Information Age Pub).

Hill, H. C., M. Blunk, C. Charalambous, J. Lewis, G. C. Phelps, L. Sleep \& D. L. Ball (2008), 'Mathematical Knowledge for Teaching and the Mathematical Quality of Instruction: An exploratory study', Cognition \& Instruction, 26, 430-511.

_- \& P. Grossman (2013), 'Learning from Teacher Observations: Challenges and Opportunities Posed by New Teacher Evaluation Systems', Harvard Educational Review, 83/2, 371-84.

Howe, C. \& M. Abedin (2013), 'Classroom dialogue: A systematic review across four decades of research', Cambridge Journal of Education, 43/3, 325-56.

Jackson, P. W. (1968), Life in the classroom (New York: Holt, Rinehart \& Wilson). Janík T. \& T. Seidel (2009) (eds.), The Power of Video Studies in Investigating Teaching and Learning in the Classroom (Münster: Waxmann).

Kane, T. J. \& D. O. Staiger (2012), Gathering feedback for teaching: Combining high-quality observations with student surveys and achievement gains (Seattle: Bill \& Melinda Gates Foundation).

Klette, K. (2004), 'Lærerstyrt kateterundervisning fremdeles dominerende? Aktivitets- og arbeidsformer i norske klasserom etter Reform 97', in K. Klette (ed.), Fag og arbeidsmåter $i$ endring? (Oslo: Universitetsforlaget).

- - (2007), 'Trends in Research on teaching and Learning in Schools: Didactics meets Classroom studies', European Educational Research Journal, 6/2, 147-61. - - (2009), 'Challenges in Strategies for Complexity Reduction in Video 
Studies: Experiences from the PISA+ Study: A Video Study of Teaching and Learning in Norway', in T. Janik \& T. Seidel (eds.), The Power of Video Studies in Investigating Teaching and Learning in the Classroom (Münster: Waxmann). - - (2015), 'Introduction: Studying Interaction and Instructional Patterns in classrooms', in K. Klette, O. K. Bergem \& A. Roe (eds.), Teaching and Learning in Lower Secondary Schools in the Era of PISA and TIMSS (Cham: Springer).

- - M. Blikstad-Balas \& A. Roe (2017), 'Linking Instruction and Student Achievement', Acta Didactica, 11/3.

- _- (2018), 'Coding Manuals as Lenses To Classroom Teaching: Measuring Teaching Qualities', European Educational Research Journal, 7/1, 129-46.

Ko, J. \& P. Sammons (2010) Effective Teaching: A review of research and evidence (Reading: CfBT Education Trust).

Lindblad, S. \& F. Sahlström (1999), 'Gamla mönster och nye gränser: Om ramfaktorer og klassrumsinteraktion', Pedagogisk Forskning i Sverige, 4/1, 93-111.

Lipowsky, F., Rakoczy, K., Pauli, C., Drollinger-Vetter, B., Klieme, E., \& Reusser, K. (2009). Quality of geometry instruction and its short-term impact on students' understanding of the Pythagorean Theorem. Learning and instruction, 19/6, 527-537.

Lyng, S. T. (2004), Være eller lære? Om elevroller, identitet og læring i ungdomsskolen (Oslo: Universitetsforlaget).

Mehan, H. (1979), Learning Lessons: Social Organization in the Classroom (Cambridge MA: Harvard University Press).

Mortimore, E. \& P. Scott (2003) (eds.), Meaning Making in Secondary Science Classrooms (Philadelphia: Open University Press).

Nilsen, T. \& J. E. Gustafsson (2016) (eds.), Teacher Quality, Instructional Quality and Student Outcomes (Amsterdam: Springer).

Nystrand, M. (1997), Opening Dialogue: Understanding the Dynamics of Language and Learning in the English Classroom (New York: Teachers College Press).

Ødegaard, M. \& K. Klette (2012), 'Teaching Activities and Language Use in Science Classrooms: Scales and Analytical Categories as Pillars for Possible interpretations', in J. Dillon \& D. Jorde (eds.), Science Education Research and Practice in Europe (Rotterdam: Sense).

OECD (2016), TALIS 2018: Video study and global video library on teaching practices (Paris: OECD).

Öhrn, E. (2012), 'Urban Education and Segregation: The responses from young people', European Educational Research Journal, 11/1, 45-57.

Pianta, R. C., K. M. La Paro \& B. K. Hamre (2008), Classroom Assessment Scoring System Manual (Charlottesville, VA: Teachstone).

Sahlström, F. (1999), Up the Hill Backwards: On interactional Constraints and Affordances for Equity-Constitution in the Classroom of the Swedish Comprehensive School, Uppsala Studies in Education 85 (Uppsala: Acta Universitatis Upsaliensis). 
Scheerens, J. (2014) 'School, teaching, and system effectiveness: Some comments on three state-of-the-art reviews', School Effectiveness \& School Improvement, 25/2, 282-90.

Seidel, T. \& M. Prenzel (2006), 'Stability of teaching patterns in physics instruction: Findings from a video study', Learning \& Instruction, 16, 228-40.

_- \& Shavelson, R. (2007), 'Teaching Effectiveness Research in the Past Decade: The Role of Theory and Research Design in Disentangling Meta-Analysis Results', Review of Educational Research, 77/4, 454-99.

Sherin, M. G. (2004), 'New perspectives on the role of video in teacher education', in J. Brophy (ed.), Using video in teacher education (New York: Elsevier Science).

Sinclair, J. \& M. Coulthard (1992), 'Towards an analysis of discourse', in M. Coulthard (ed.), Advances in spoken discourse analysis (London: Routledge). Stigler, J. W. \& J. Hiebert (1999), The teaching gap: Best ideas from the world's teachers for improving education in the classroom (New York: Free Press).

Thomas, G. (2007), Education and theory: Strangers in paradigms (Maidenhead: Open University Press). 